INTERNATIONAL DESIGN CONFERENCE - DESIGN 2018

https://doi.org/10.21278/idc.2018.0159

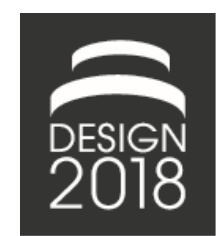

\title{
SHAPING PRODUCTS: DIFFERENCES BETWEEN EXPERT AND NOVICE INDUSTRIAL DESIGNERS
}

\author{
S. Jagtap
}

\begin{abstract}
The process of shaping a product's visual appearance is crucial in determining consumer response. However, extant research on the nature of expertise in this process is scarce. Specifically, there is absence of studies investigating differences between how expert and novice industrial designers use information in this process. This research, using think aloud method, compared informational behaviour of an expert and a novice industrial designer in shaping products. We report rich qualitative accounts of their informational behaviour, revealing a sharp contrast between them.
\end{abstract}

Keywords: industrial design, aesthetics, sketching, product styling, visual appearance

\section{Introduction}

The visual appearance of products affects consumer perception and evaluation of product properties (Hekkert, 2006). Industrial designers play a key role in shaping a product's visual appearance, influencing consumer response and product success (Warell, 2001; Crilly et al., 2009; Jagtap and Jagtap, 2015). In the design process, they may access and use information on a variety of topics, e.g. information on products of clients and competitors, styling trends, etc.

Whilst several studies have been devoted to studying how consumers respond to products (Orth and Malkewitz, 2008), design researchers have given relatively little attention to the process of shaping a product's visual appearance (Crilly et al., 2009; Jagtap and Jagtap, 2015). Recent studies also stress the need of more research on descriptive accounts of designers' activities in shaping products, highlighting the paucity of research on this subject (e.g. Jagtap, 2017; Sörensen et al., 2016).

The process of shaping a product's visual appearance demands a considerable level of skill and expertise (Tovey et al., 2003). It is crucial to understand the nature of expertise in this process. There is, however, a limited knowledge on the nature of design expertise in shaping products. Specifically, there is a lack of knowledge about the differences between expert and novice designers' use of information in shaping products, limiting our ability to provide useful guidance for training novice designers. The present research aims at understanding how expert and novice industrial designers use information in the process of shaping a product's visual appearance. This is expected to generate important knowledge not only for supporting the practice and education of designing a product's visual appearance, but also for establishing future research directions in this field. For example, the knowledge about the differences between novice and expert designers is useful to train novices in learning strategies of expert designers to develop successful products. Whilst industrial designers contribute to many aspects of designing products, this paper focuses on a specific part of their role, i.e. how they shape a product's visual appearance. Before proceeding further, a note on the use of terminology is necessary - the terms 'visual form' and 'form' are used interchangeably, and denote the visual appearance of products. 


\section{Background literature}

\subsection{Shaping visual appearance of products}

A few studies have explored general characteristics of the form design process. Crilly et al. (2009) developed a framework of factors affecting this process of shaping products. Their empirically grounded framework, based on interviews with industrial designers, represents: the intended consumer response that designers attempt to embody in the design of a product's visual form, activities (e.g. sketching) of designers in shaping products, and different moderating factors such as manufacturing issues, team characteristics, preferences of clients and designers, etc. Bangle (2001) has described the general personalities and roles of industrial designers as well as communication problems between industrial designers and engineers in the car industry. In addition to the above studies reporting general characteristics of the process of shaping products, some studies have examined how designers attempt to elicit strategic intentions to foster brand recognition through product design (Karjalainen and Snelders, 2010).

Crilly and Clarkson (2006), based on interviews with industrial designers and consumer researchers, have examined the role of consumer information in the form design process and difficulties associated with collecting and interpreting this information. They found that information about consumers helps designers to understand how products are perceived, to establish the direction of future projects, and to gain feedback on completed ones. In shaping products, designers may also use information on similar products (e.g. products within the category of the product that is being designed) or dissimilar products (e.g. products from other categories) to seek inspiration for idea generation (e.g. Crilly et al., 2009). In the field of engineering design, several studies have been undertaken to examine informational behaviour of engineering designers (e.g. Marsh, 1997; Jagtap and Johnson, 2010). A number of studies, undertaken in laboratory settings with experienced engineering designers or students, note the importance of information in the engineering design process (Eris, 2002; Jagtap et al., 2014a). As compared to these studies that are undertaken the field of engineering design, the informational behaviour of industrial designers in the form design process has been under-researched.

\subsection{Novices and experts}

Investigating differences between novices and experts in their ways of working and delivering performance in a domain helps understand effect of experience on performance, permitting the development of methods to support novices in learning expert-strategies. As such, differences between problem solving behaviours of novices and experts have been investigated in many professions and domains (e.g. Chi et al., 1981). For example, empirical research in the field of medical decision making suggests that experts appear to select a preferred option early in the process, allowing them to avoid searching through irrelevant and large amount of information (e.g. Patel et al., 2002). Furthermore, studies of novices and experts in fields such as sports (in tennis, see Rowe and McKenna, 2001; in dancing, see Smyth and Pendelton, 1994), games (in chess, see Chase and Simon, 1973), and problem solving in physics (e.g. Chi et al., 1981) and finance (Hershey et al., 1990) have revealed systematic differences between their ways of delivering performance and problem-solving behaviours. The findings from such studies indicate that experts can effectively recall relevant information, with effective prioritization of information seeking tasks. They also spend more time in considering information in the problem space (Chi et al., 1981), and they are able to predict information that will be needed later in the process (e.g. Hershey et al., 1990).

Studies comparing novices and experts tend to be undertaken in domains focussing on relatively welldefined tasks having a clear initial state, goal state and a set of rules which can be followed to achieve the goal state (e.g. Simon, 1973). In contrast, there is a relatively small amount of research on expertise in design, a creative knowledge field, dealing with ill-defined problems with many vague problem parameters (e.g. Björklund, 2013). In design, empirical studies of novices and experts have been undertaken with product designers (e.g. Ho, 2001), engineering designers (e.g. Cross and Clayburn Cross, 1998; Atman et al., 1999; Ahmed et al., 2003; Ball et al., 2004), weaving designers (e.g. Seitamaa-Hakkarainen and Hakkarainen, 2001) and architects (Kavakli and Gero, 2002). For example, Ho's (2001) protocol study of a novice and an expert designer revealed that the expert designer employed explicit problem decomposition which was not observed in the novice designer's process. Likewise, using protocol studies, Kavakli and Gero (2002) compared cognitive activities of novice and 
expert architects, suggesting that the expert architects control their cognitive activities more efficiently than novices and that they are more cognitively organised and active than novices. Ahmed et al.'s (2003) empirical study comparing novice and experienced engineering designers found that the novices generated a design change, evaluated it and generated another change, employing a 'trial and error' method. On the other hand, the experienced designers undertook preliminary evaluation of design changes before carrying out a final, comprehensive evaluation. In addition, the experienced designers used information from previous projects and analysed information on problems more critically.

Overall, it seems that as compared to studies on expertise in solving well-defined problems, there is scarce research on design expertise. This research on design expertise is predominantly undertaken in fields such as engineering design or architectural design. Extant research on understanding expertise in shaping products is scarce. Specifically, there is absence of studies investigating differences between expert and novice designers' use of information in shaping visual appearance of products.

\section{Research methodology}

\subsection{Experimental design}

To address the aim of exploring how novice and expert industrial designers use information in shaping a product's visual appearance, we used the experimental method of think-aloud protocol analysis - a widely used method in design research (Chai and Xiao, 2012). Because a design process can be influenced by a variety of factors such as the type of problem, experience of designers, etc., an ideal experiment would vary only one factor while keeping the remaining factors constant. In the present study, two industrial designers participated in the experiments (one expert and one novice), and each of them worked on the same design problem individually. This sample size is sufficient as our aim was to explore some aspects of the under-researched field of shaping a product's visual appearance. In addition, this sample size effectively permitted undertaking close examination of the two designers' information use, and allowed us to report the details of qualitative analysis and findings in the present paper, within the constraint on the number of pages. Previous studies exploring some aspects of engineering design or architectural design have used similar sample size to explore some aspects of an under-researched design area, while providing details of findings (e.g. Dwarakanath and Blessing, 1996; Ho, 2001; Chandrasekera et al., 2013).

\subsection{Participants}

While the expert designer, aged 50 years, has 25 years of experience in the field of industrial design, the novice designer, aged 22 years, is a Masters student in industrial design and has no experience of working as a professional industrial designer. Both are born and raised in Sweden. Henceforth, the expert designer is called Eric and the novice Nikita - their names are changed to maintain anonymity. Following the criterion of professional design experience used in previous research (e.g. Dixon, 2011; Ozkan and Dogan, 2013), Eric is an expert designer and Nikita a novice designer.

\subsection{Procedure}

The think-aloud method is useful in revealing the subjects' thinking process. However, the subject may not feel comfortable with speaking thoughts as he/she engages in problem solving. Therefore, it is necessary to train the subjects in speaking his/her thoughts. Therefore, before the experiments, we trained the subjects in speaking their thoughts with a warm-up task. The following steps were followed with each of the two designers: (1) explanation of the research method (about 15 minutes), (2) warm-up task (about 30 minutes), and (3) solving the design problem (maximum 180 minutes). When a designer paused speaking thoughts for a longer period of time, a researcher, who was present during the entire experiment, reminded the designer to think aloud. The experiments resulted into data consisting of video and audio recordings plus written materials and sketches of the designers.

\subsection{Design problem}

To formulate the design problem, we considered several criteria. The design problem must be suitable for both the expert and novice designers, and must be within the field of shaping a product's visual 
appearance. The problem also needs to present a fairly realistic design task. Based on such criteria, we formulated the design problem of shaping the visual appearance of a stapler. A company designing staplers was identified through Internet searches of stapler designers and manufacturers. In the present paper, this company is called Stexel (the name is changed). The problem involved the task of shaping visual appearance of an innovative stapler being developed by Stexel (see Figure 1). The design task is new to the designers. In addition, the problem is not very large to capture and analyse the data. After the experiments, both novice and expert designers mentioned that the problem was new to them.

Stexel is a highly recognised company designing and manufacturing office
products. The company markets products in more than 80 countries. Stexel is
the brand leader in many product categories - binding and laminating,
stapling and punching, and notebooks. The R\&D unit of Stexel has been
successful in creating a highly novel material for the internal mechanism of
its staplers. By using this novel material in the internal mechanism, Stexel has
developed an innovative stapler called 'Micro-Force'. The size of Micro-
Force and its internal mechanism are like those of the stapler placed on your
table, but the materials used in its internal mechanism are novel. Micro-Force
is free of 'staple jams'. It can staple up to 25 A4-sized sheets smoothly with
very small force - about 10\% of the force required in comparable staplers
available on market. Micro-Force is recognized as one of the greatest
innovations in the stapler industry. It is a manually operated and hand-held
stapler. It is suitable for homes and offices. Stexel intends to market it in more
than 80 countries. Stexel has contacted you as an industrial designer. Stexel
wants you to shape the visual appearance of Micro-Force. Stexel has given
you all the required information in the folder titled 'given information'.

Figure 1. The form design task used in the experiments

The designers were given a folder titled 'given information' which included information on the brief history of Stexel and timeline of its products. The folder also included information on Stexel's and competitors' staplers, e.g. their images and prices. This information on Stexel's and competitors' staplers was obtained from the website - www.amazon.co.uk. In addition to the printed information included in the 'given information' folder, a hand-held office stapler was also provided to the designers.

\subsection{Data analysis}

The audio recordings were transcribed. We reviewed the transcripts along with video recordings. The analysis was qualitative and exploratory; when the designer engaged with information accessing, using, interpreting, etc. in some way, it was noted. We did not bring any pre-formulated categories or notions of what we would observe. Thus, the method of continual refinement was followed (e.g. Strauss, 1987; Harrison and Minneman, 1996). The analysis resulted into rich qualitative accounts of the novice and expert designers' use of information in their process of shaping the product's visual appearance.

\section{Findings}

While Nikita finished the design task in 69 minutes, Eric finished it in 190 minutes, i.e. he took 10 more minutes than the allocated time. Nikita and Eric generated 9 and 2 conceptual solutions, respectively. Their final conceptual solutions are presented in Figure 2. In the sections that follow, we present our observations of their information use. 

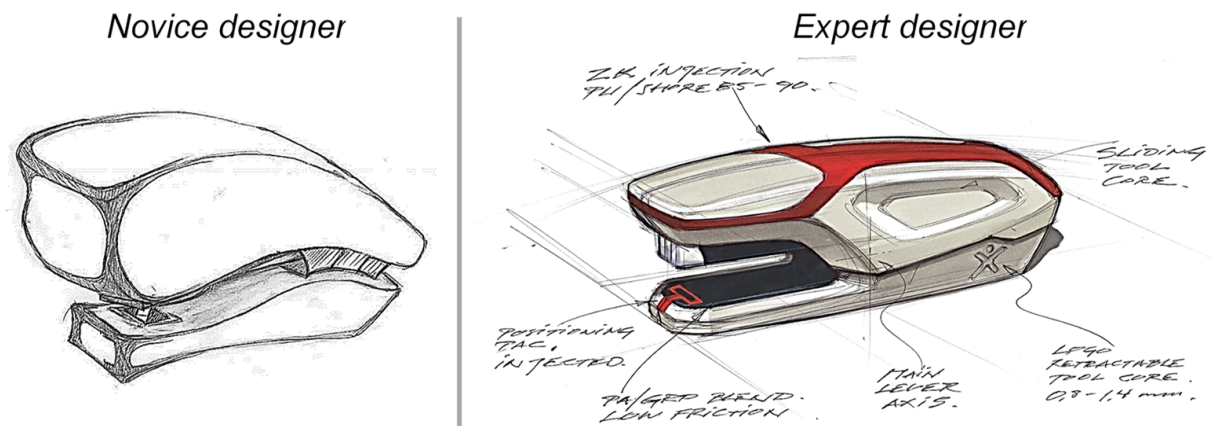

Figure 2. Final conceptual solutions of the novice and expert designers

\subsection{Expert designer}

\subsubsection{Portraying the client}

Understanding the client's needs and gaining insights into his/her product portfolio and design philosophy is instrumental in shaping the design work commissioned by the client. Characterising the client thus directs the further design work. Having read through the design brief, Eric, using his prior experience and knowledge, interprets several characteristics of Stexel such as 'dominant' and 'moderate to conservative', and speculates on manufacturing methods that might be available at Stexel:

"okay, so first I try to kind of understand the brief, that means ... first of all understanding the client, this is a very broad client...to a wide range of market segments, that means that they most likely will be moderate to conservative in terms of how they regard their product" (00:07:11)

"they are used to buying high volumes which means that pricing is always top priority and will automatically provide us with certain manufacturing methods" (00:08:31)

Further on, while reading the given information about the client company, Eric develops an 'image' of Stexel, characterising it as an 'engineering-oriented' and Japanese or Swiss company:

"they launched filing range in 2013, when everything is basically digital, it is still a very mechanical ... must be quite engineering-oriented company, it is British, but the character of the company is almost Japanese or Swiss" (00:13:50)

Later, Eric gathers information on existing staplers of Stexel from the 'given information' folder. $\mathrm{He}$ carefully reads retail prices of Stexel's staplers, and estimates their retail margin, distribution cost, and production cost. This interpretation of the gathered information and cost estimation is used to confirm the image of Stexel that he creates early in the session:

"simple ... confirms the moderate to conservative design attitude of the client" (00:26:45)

\subsubsection{Characterising the market and project}

In addition to creating an 'image' of Stexel, Eric tries to characterise the market and commissioned project:

"project is innovative, attitude of client is most probably conservative, moderate to conservative ... even though the development department will stress innovation, the sales and management will most likely have a more slower acceleration of innovation attitude, although that is less consistent today than it used to be, because markets are changing more rapidly" (00:10:21)

\subsubsection{Semantic positioning}

Because product failures in competitive markets could have serious financial consequences for companies, professional industrial designers may attempt to design a product's visual appearance such that it will successfully compete with competitors' products, while avoiding 'cannibalisation' of the client's existing products. This requires appropriate semantic positioning of the product being designed. In developing the semantic position of the product, designers may access, interpret and synthesise 
information related to products of competitors as well as those of the client. There are several examples of such information accessing and interpretation by Eric when he develops semantic position of the Micro-Force. In developing this sematic position, Eric first engages in formulating the 'price position' and 'function position' of the Micro-Force. To formulate 'price position', Eric seeks information on retail prices of Stexel's and competitors' products, and tries to estimate their different costs:

"now this is retailer, eleven pounds, normally I would most probably get the cost price from the... maybe it's coming up in the information here, but what I'm doing now is I can calculate backwards a little bit, what I have to play with" (00:20:27)

"post retail margin, and there is probably a distributor, 50 percent mark-up is 3.30, distribution price is base for 3.30 times, one pound less, 2.30 ... gross net selling price” (00:24:05)

Further on, Eric compares attributes, colours and materials of Stexel's and competitors' products in his endeavour of formulating 'price position' of Micro-Force:

"a little funky, blue-green, but very competitive price ... also here, conservative colours, conservative styling, extremely low price, no discount, sometimes they dare to go with a transparent ABS or acetal, so the material has to be really sturdy, so it has to be an impact-improved ABS... impact-modified acetal could also..." (00:28:10)

Later, Eric assimilates the above information on prices and other characteristics of Stexel's and competitors' products as well as information on Micro-Force from the design brief, to estimate 'price position' of the Micro-Force:

"the Micro-Force ... its internal mechanism is mechanical, but the effect is like it was operated by assisted power like an electrical, it's like mechanical power aid, so now I will take a quick look at the electrical staplers, they are in a totally different price range, so this product is going to be somewhere in between the electrical and the mechanical, we have electrical staplers, price range 40 to 120 pounds, then we have the mechanical staplers, price range 3 to 30 something” (00:33:24)

"if the mechanical Micro-Force is cheap to produce, does not create staple jams, and very smooth, they will kill basically 80 percent of their own product portfolio, so we could motivate the slightly higher price" (00:34:20)

Eric then formulates the 'function position' and 'semantic position' of Micro-Force between electric and mechanical staplers:

"the Micro-Force is ending up in terms of function and product semantics, in between the electrical staplers and the mechanical staplers" (00:34:55)

Eric's semantic positioning of Micro-Force appeared to be influenced by his estimation of price and function of Micro-Force. And, both price and function positioning of Micro-Force are based on his prior work of portraying the client and characterising the market and project. Eric makes a diagrammatic representation of Micro-Force's semantic position, see Figure 3(A). This figure might illustrate Eric's internalised or intuitive conceptualisation of Micro-Force's semantic position that he formulated.

\subsubsection{Identifying common form features}

In shaping a product's visual form, designers may attempt to differentiate the product being designed from those of the client and competitors, while embodying the recognition of the client's brand in the visual appearance of the product being designed. In other words, the product may be designed in such a way that it will fit the newly created semantic position while inheriting recognisable or common form features of some or all products of the client. This may require the designer to identify recognition-creating form features of the client's products. This identification of recognition-creating form features was observed in Eric's design work, as manifested by his use of information from the 'given information' folder. He compares products of Stexel with each other. He also compares products of competitors using both 'within' (i.e. comparing products of a given competitor with those of the same competitor) and 'between' comparison (i.e. comparing products of a given competitor with those of other competitors). To aid the comparison, he uses several criteria such as colours (e.g. silver black), geometry (e.g. 'angle', 'flat', 'ellipse', 'flat negative 
end'), logos, materials, manufacturing methods, attributes (e.g. 'adult toy', 'industrial', 'strange', 'dramatically different'), and product type (e.g. hand-held stapler, desktop stapler, electric stapler).
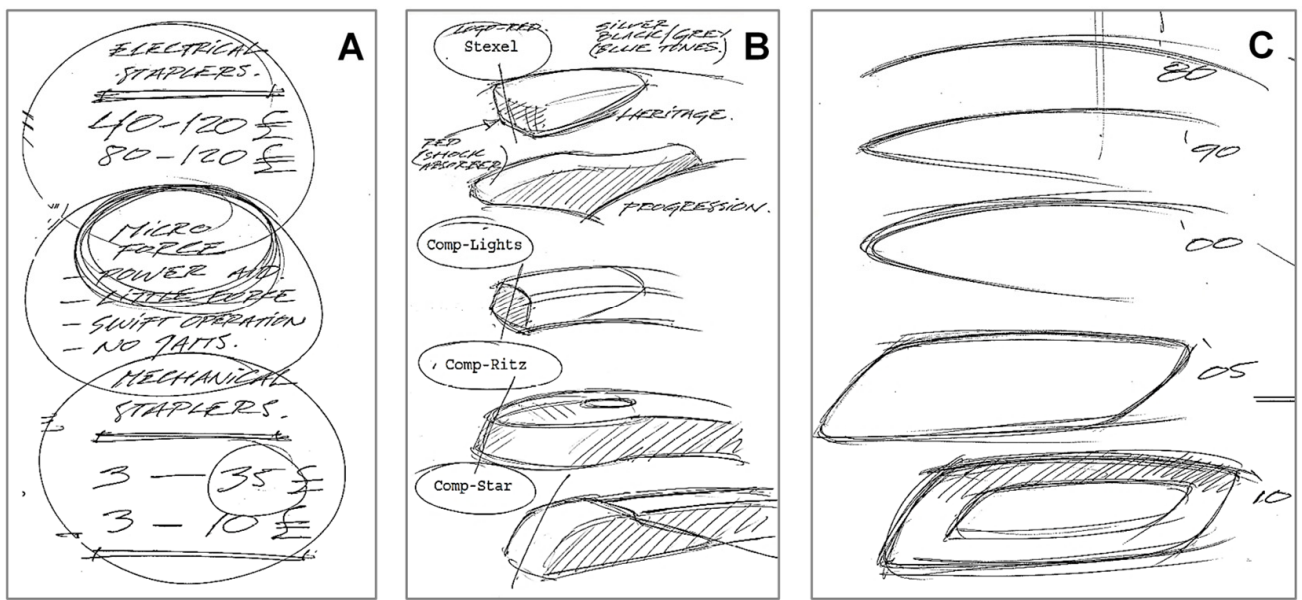

Figure 3. (A) the expert designer's diagrammatic representation of the semantic position of Micro-Force; (B) his sketches showing recognition-creating features of Stexel's and competitors' products; $(\mathrm{C})$ his sketches showing styling trends

Comparison of Stexel's product:

"okay design characteristics, flat end, round end, flat negative end, round end, round end angle, angle, angle, same thing over here, angle, round view angle, angle reversed, angle, angle extruded, differing, looks like an adult toy, but that's really... Stexel Joy stapler, really strange, here we have the angled ... it's the rubber insert" (00:46:41)

"that's an OEM product, not to consider in the design program, too dramatically different, this one also ... even the more funky ones with the transparent plastics have the ellipse on insert" (00:51:34)

Comparison of competitors' products (Comp-Lights, Comp-Ritz, Comp-Quiz and Comp-Star are competitors of Stexel - their names are changed):

"okay so now we look at the competitors, Comp-Lights, radius character, Comp-Ritz, Comp-Lights, CompRitz ... Comp-Quiz, Comp-Lights, radius, radius the other way, Comp-Lights, evidently it is working with a kind of extruded look, one material, then the handle is extruded, Comp-Ritz, they seem to go all over the place with their design" (00:56:00)

"Comp-Star, they have this added... Comp-Star, this open convex shape, they're doing a little bit a take on Comp-Ritz, same again, same again, Comp-Ritz, ellipsoid, cut off in the back, same there, same there" (01:00:00)

Later, Eric sketches the common or recognition-creating form features of Stexel's and competitors' products, see Figure 3(B).

\subsubsection{Using information on dissimilar products}

Prior to concept generation, Eric remembers some products used in offices and homes, probably to seek inspiration for the purpose of generating ideas. He thinks about several products such as lamps, pens, keyboard, etc.:

"so now we are probably ready to go, what else do you have in the office that we might consider relevant, as the stapler is an interior design object, or should at least be considered one ... in a perfect world I would probably look at desktop lamps for reference" (01:22:46)

"to have a more aggressive design proposal, I might look at gaming ... gaming product components, keyboards, mouse ... not that the young generation are particularly excellent at keeping order with their papers, but they will grow up, keyboards, lamps ... computers in general, pens" (01.24.00) 


\title{
4.1.6. Assimilating styling trends
}

In addition to identifying recognition-creating form features of Stexel's and competitors' products, Eric, from his memory, accesses information on styling trends, and explicitly formulates a requirement to integrate current styling trends with Stexel's tradition:

\begin{abstract}
"at the same time I know that the rest of the world of design is moving in a fast pace towards polygonal shapes, so if we in the 90's had the kind of a soap box attitude, or 80's, in the 90's we started to get these grid lines and ellipsoids, where Stexel still is. progressive design language is moving towards polygonal surfaces, or even off-set polygonal surfaces, evident example of that is looking at tail lights in the car industry for example ... so we have 80's, 90's, 2000, 2005, 2010 ... so for this product to be perceived modern I need to integrate some of this attitude carefully with Stexel's tradition" (01:36:05)
\end{abstract}

Eric also sketches his understanding of styling trends, see Figure 3(C). Eric's informational behaviour is discussed further in Section 5.

\subsection{Novice designer}

Having read through the design brief, Nikita accesses information on Stexel's history and timeline of its products from the 'given information' folder. However, thorough analysis and use of the accessed information is not evident. She even discards the need of that information:

"so... given information about Stexel, here's a history timeline chart, over from when the company started and what they have produced" (00:03:03)

“... yeah, they have a lot of staplers. but all are quite ... like this one ... so this is not really needed" (00:04.08)

Further on, she looks at information on staplers of competitors, and simply discards the need of that information:

"staplers from competitors, don't really think that this is needed..." (00:04.18)

Later, she mainly works on generating solutions, and engages in sketching, while describing the geometrical aspects of the solutions:

"I am trying to make the form a bit more round ... I see if I can make these two lines meet each other ... upwards and done" (00:06.37)

She continues sketching and describing generated forms in the later part of her process:

"maybe taking it down a bit in the back and putting a curve that will continue from this place up ... making it a bit smoother" (00:12.37)

"maybe the bottom should go out a bit ... and then have a corner here inwards ... having a corner here" (00:30.00)

"this should have a bending curve ... then straight here" (00:54.00)

As mentioned earlier, Nikita generated 9 conceptual solutions; whereas Eric generated just two solutions. Figure 4 shows some solution sketches generated by Nikita.

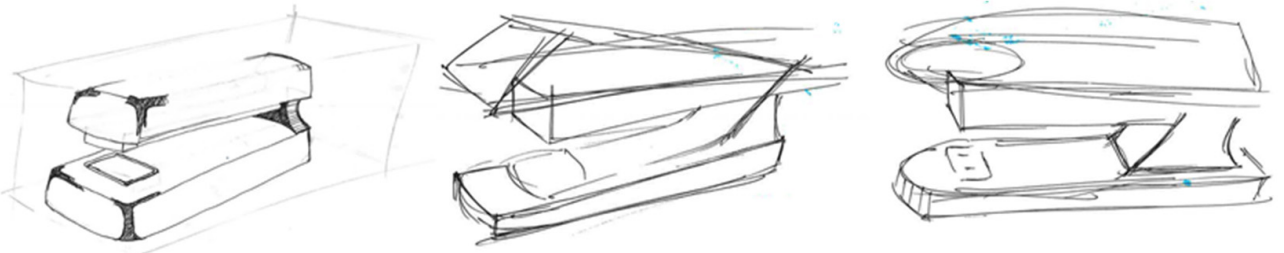

Figure 4. Some solution sketches generated by the novice designer

Accessing, interpreting and using relevant information was virtually absent in the novice designer's process of shaping the product's visual appearance. The novice designer spent most of her time on generating, sketching and describing conceptual solutions; and thus, it seems that her process predominantly used solution-oriented design behaviour, lacking structured use of information and problem analysis. 


\section{Summary of findings, discussion and conclusions}

The findings reveal a sharp contrast between the informational behaviour of the novice and the expert designer. These findings are gleaned by using the experimental method of think aloud protocol analysis, and thus has limitations associated with this method. Although the sample size in our study is small, the experiments provided sufficient data and permitted its close analysis. Further research in this field can gain by analysing data from a large number of designers, permitting statistical analysis. The differences between the expert and novice designers, as explored in this study, might also be attributed to differences between their gender and age, although age related differences are common in novice and expert designers due to differences between their amount of experience. Future research can compare novices and experts, balancing gender and age-related differences. Whilst this research focused on shaping a product's visual appearance, dealing mainly with the visual sense in product design, future research can consider other senses, while employing interviews and questionnaires as data collection methods to examine 'real' design projects. Our analysis generated new and important insights into the informational behaviour of the participating designers, while allowing rich and detailed reporting of findings in this conference paper, which can usefully provide a basis for further research in this field.

Based on his analysis and interpretation of the accessed information, the expert designer identified several issues related to the problem at hand in a breadth oriented manner. He used the information mainly in understanding the problem; this is diagrammatically illustrated in Figure 5. He formulated the sematic position of the product being designed (i.e. Micro-Force) after determining its 'function position' and 'price position' - both function and price of Micro-Force were positioned between mechanical and electric staplers. He also identified recognition-creating features of the client's and competitors' products by seeking information on their prices, colours, attributes (e.g. 'funky', 'industrial, etc.), geometry (e.g. 'flat end', 'round', 'ellipsoid'), materials, and manufacturing methods. Another major activity that he undertook in understanding the problem was identification of styling trends. He later developed holistic concepts, which appeared to be influenced by the issues he identified in problem analysis, resulting into a more balanced conceptual solution.

The expert designer's focused and systematic use of information in understanding the problem concurs with previous findings of expertise in other fields of design, e.g. engineering design (Ahmed et al., 2003; Adams et al., 2003; Cross, 2004; Popovic, 2004). The expert designer in the present study extensively analysed the problem at hand by accessing, interpreting and using information on a wide range of topics. The expert designer's informational behaviour in the protocol study might have been influenced by his 25 years of experience in the field of industrial design. He has worked on many form design projects, involving interaction with a variety of stakeholders such as clients, retailers, marketers, manufacturers, and so on. It is highly likely that the expert designer has a sound understanding of factors that affect the success of a product in competitive markets. The accumulation and development of his knowledge and skills in using information might have influenced his informational behaviour in the experiment; thus, reflecting some aspects of his 'real' informational behaviour.

In contrast to the expert designer, the novice designer's use of information in the form design task was virtually absent, resulting into the lack of explicit design requirements and problem analysis. This informational behaviour of the novice designer is in line with the results of Lloyd and Scott's (1995) study of architects. The novice designer seemingly did not use information on client's products, competitors' products or dissimilar products. In addition to this virtual absence of information use, the novice designer did not engage in problem understanding, not employing activities such as function positioning, price positioning, semantic positioning, identifying typical form features of client's and competitors' products, and identifying styling trends. Lack of experience of working on a variety of 'real life' design projects might have affected the novice designer's informational and problem understanding behaviour. The novice designer mainly engaged in generating and sketching solutions. This behaviour of the novice designer about generating many solutions concurs with Lai et al.'s (2008) study in which they found that freshmen students generated many solutions than more experienced designers. Figure 6 illustrates the novice designer's process of shaping the product.

Whilst the expert designer and the novice designer generated 2 and 9 conceptual solutions respectively, both concepts of the expert designer appear to be better than all concepts of the novice designer in terms of their ability to address the given design problem. However, further research is required to 
systematically assess their concepts, for example, by seeking feedback from potential consumers. It would be interesting to understand how expert and novice designers redesign the product based on the feedback received from the client or consumers.

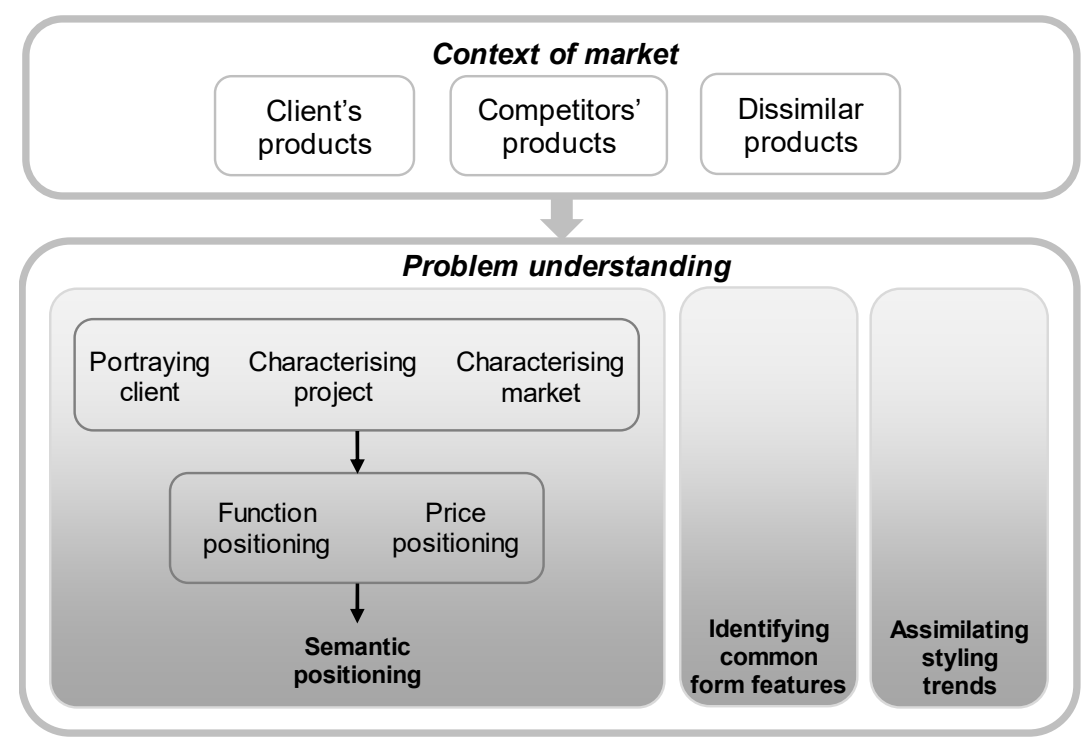

Figure 5. The expert designer's information use in shaping the product

Some authors have suggested that the process of shaping products is tacit and intuitive in nature (e.g. Tovey, 1997; Jagtap and Jagtap, 2015). In contrast to such suggestions, our research has indicated that some aspects of this process can be systematic, structured, and can be revealed by the think aloud protocol method, as suggested by the informational behaviour of the expert designer. It would be interesting and important to identify more such aspects of the form design process. In-depth understanding of such aspects can provide a sound foundation upon which user-friendly tools and methods can be developed to support the practice of shaping products (e.g. Jagtap et al., 2014b).

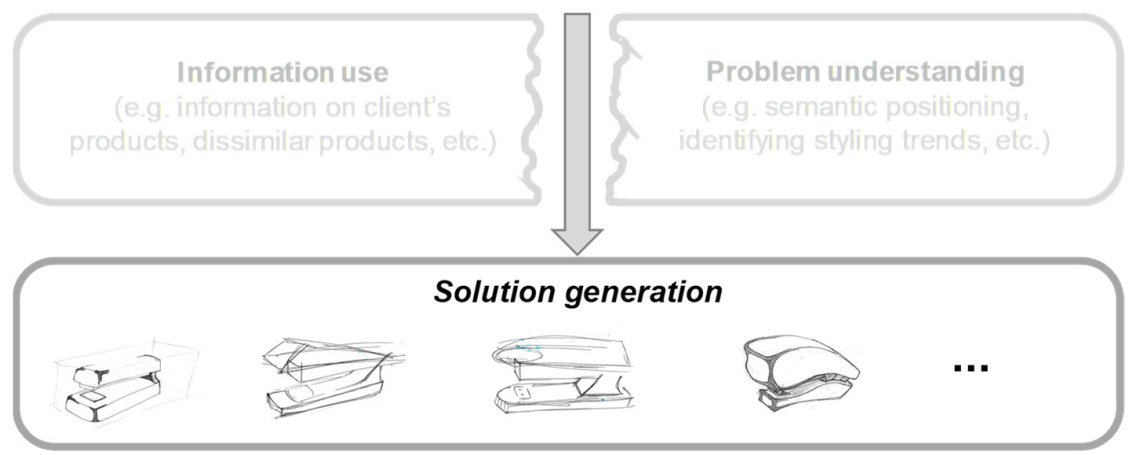

Figure 6. Illustration of the novice designer' process of shaping the product

The findings of this research might usefully assist the development of pedagogical interventions to support novice designers in using information in the process of shaping products. For example, a design teacher can develop appropriate assignments, asking students to compare form features of client's and competitors' products for identifying commonalities and differences in their visual appearance. Assignments can also be developed to identify current styling trends and to formulate the semantic position of the product being designed. Such targeted assignments can later be followed by form design projects, requiring students to integrate their knowledge and skills learned in the previous assignments. Whilst this research employed the think aloud protocol method, future research might usefully employ other methods such as observations, interviews or questionnaires to identify differences between novice and expert designers' ways of shaping products. 


\section{Acknowledgment}

We are grateful to the designers for generously giving their time to participate in the experiments. We would also like to thank Crafoord Foundation, Sweden (20150975) for financial support.

\section{References}

Adams, R.S., Turns, J. and Atman, C.J. (2003), "Educating effective engineering designers: the role of reflective practice”, Design Studies, Vol. 24 No. 3, pp. 275-294. https://doi.org/10.1016/S0142-694X(02)00056-X

Ahmed, S., Wallace, K.M. and Blessing, L.T.M. (2003), "Understanding the differences between how novice and experienced designers approach design tasks", Research in Engineering Design, Vol. 14 No. 1, pp. 1-11. https://doi.org/10.1007/s00163-002-0023-z

Atman, C.J., Chimka, J., Bursic, K.M. and Nachtmann, H.L. (1999), “A comparison of freshman and senior engineering design processes", Design Studies, Vol. 20 No. 2, pp. 131-152. https://doi.org/10.1016/S0142694X(98)00031-3

Ball, L.J., Ormerod, T.C. and Morley, N.J. (2004), "Spontaneous analogising in engineering design: a comparative analysis of experts and novices", Design Studies, Vol. 25 No. 5, pp. 495-508. https://doi.org/10.1016/j.destud.2004.05.004

Bangle, C. (2001), “The ultimate creativity machine: How BMW turns art into profit", Harvard Business Review, Vol. 79 No. 1, pp. 47-55.

Björklund, T.A. (2013), "Initial mental representations of design problems: Differences between experts and novices”, Design Studies, Vol. 34 No. 2, pp. 135-160. https://doi.org/10.1016/j.destud.2012.08.005

Chai, K.H. and Xiao, X. (2012), "Understanding design research: A bibliometric analysis of Design Studies (19962010)", Design Studies, Vol. 33 No. 1, pp. 24-43. https://doi.org/10.1016/j.destud.2011.06.004

Chandrasekera, T., Vo, N. and D'Souza, N. (2013), "The effect of subliminal suggestions on Sudden Moments of Inspiration (SMI) in the design process", Design studies, Vol. 34 No. 2, pp. 193-215. https://doi.org/10.1016/j.destud.2012.09.002

Chase, W.G. and Simon, H.A. (1973), “The mind's eye in chess", In: Chase, W.G. (Ed.), Visual information processing, Academic Press, New York, pp. 215-308. https://doi.org/10.1016/B978-0-12-170150-5.50011-1

Chi, M.T.H., Feltovich, P.J. and Glaser, R. (1981), "Categorization and representation of physics problems by experts and novices", Cognitive Science, Vol. 5 No. 2, pp. 121-152. https://doi.org/10.1207/s15516709cog0502_2

Crilly, N. and Clarkson, P. (2006), "The influence of consumer research on product aesthetics", Proceedings DESIGN 2006, the 9th International Design Conference, Dubrovnik, Croatia.

Crilly, N., Moultrie, J. and Clarkson, P.J. (2009), "Shaping things: intended consumer response and the other determinants of product form", Design Studies, Vol. 30 No. 3, pp. 224-254. https://doi.org/10.1016/j.destud.2008.08.001

Cross, N. and Clayburn Cross, A. (1998), "Expertise in Engineering Design”, Research in Engineering Design, Vol. 10 No. 3, pp. 141-149. https://doi.org/10.1007/BF01607156

Cross, N. (2004), "Expertise in design: an overview", Design Studies, Vol. 25 No. 5, pp. 427-444. https://doi.org/10.1007/BF0160715610.1016/j.destud.2004.06.002

Dixon, R. (2011), "Selected Core Thinking Skills and Cognitive Strategy of an Expert and Novice Engineer", Journal of STEM Teacher Education, Vol. 48 No. 1.

Dwarakanath, S. and Blessing, L.T.M. (1996), "Ingredients of the design process: a comparison between group and individual work", In: Cross, N., Christiaans, H. and Dorst, K. (Eds.), Analysing design activity, Wiley, Chichester, UK.

Eris, O. (2002), Perceiving, comprehending, and measuring design activity through the questions asked while designing, PhD thesis, Stanford University, Stanford.

Harrison, S. and Minneman, S. (1996), "A bike in hand: A study of 3-D objects in design. Analysing design activity", In: Cross, N., Christiaans, H. and Dorst, K. (Eds.), Analysing design activity, Wiley, Chichester, UK.

Hekkert, P. (2006), "Design aesthetics: principles of pleasure in design”, Psychology science, Vol. 48 No. 2, pp. 157-172.

Hershey, D.A., Walsh, D.A., Read, S.J. and Chulef, A.S. (1990), "The effects of expertise on financial problem solving: evidence for goal-directed, problem-solving scripts”, Organizational Behavior and Human Decision Processes, Vol. 46 No. 1, pp. 77-101. https://doi.org/10.1016/0749-5978(90)90023-3

Ho, C.-H. (2001), "Some phenomena of problem decomposition strategy for design thinking: differences between novices and experts", Design Studies, Vol. 22 No. 1, pp. 27-45. https://doi.org/10.1016/S0142694X(99)00030-7 
Jagtap, S. (2017), "Intentions and Inspiration in Shaping Visual Appearance of Products: The Practice of Professional Industrial Designers in India", The Design Journal, Vol. 21 No. 1, pp. 85-107. https://doi.org/10.1080/14606925.2018.1396075

Jagtap, S. and Jagtap, S. (2015), "Aesthetic design process: Descriptive design research and ways forward", International Conference on Research into Design, ICoRD'15, pp. 375-385.

Jagtap, S. and Johnson, A. (2010), "Requirements and use of in-service information in an engineering redesign task: Case studies from the aerospace industry", Journal of the Association for Information Science and Technology, Vol. 61 No. 12, pp. 2442-2460. https://doi.org/10.1002/asi.21427

Jagtap, S., Larsson, A., Hiort, V., Olander, E., Warell, A. and Khadilkar, P. (2014a), "How design process for the Base of the Pyramid differs from that for the Top of the Pyramid", Design Studies, Vol. 35 No. 5, pp. 527-558. https://doi.org/10.1016/j.destud.2014.02.007

Jagtap, S., Warell, A., Hiort, V., Motte, D. and Larsson, A. (2014b), "Design methods and factors influencing their uptake in product development companies: a review", Proceedings of International Design Conference 2014, Dubrovnik, Croatia.

Kavakli, M. and Gero, J. (2002), "The Structure of Concurrent Cognitive Actions: a case study on novice and expert designers”, Design Studies, Vol. 23 No. 1, pp. 25-40. https://doi.org/10.1016/S0142-694X(01)00021-7

Lai, J.Y., Roan, E.T., Greenberg, H.C. and Yang, M.C. (2008), "Prompt versus problem: helping students learn to frame problems and think creatively", Third International Conference on Design Computing and Cognition, Atlanta, USA, pp. 1-6.

Lloyd, P. and Scott, P. (1995), "Difference in similarity: interpreting the architectural design process", Environment and Planning B: Urban Analytics and City Science, Vol. 22 No. 4, pp. 383-406. https://doi.org/10.1068/b220383

Marsh, J.R. (1997), The Capture and Utilisation of Experience in Engineering Design, PhD thesis, University of Cambridge, UK.

Orth, U.R. and Malkewitz, K. (2008), "Holistic package design and consumer brand impressions", Journal of Marketing, Vol. 72 No. 3, pp. 64-81. https://doi.org/10.1509/jmkg.72.3.64

Ozkan, O. and Dogan, F. (2013), "Cognitive strategies of analogical reasoning in design: Differences between expert and novice designers", Design Studies, Vol. 34 No. 2, pp. 161-192. https://doi.org/10.1016/j.destud.2012.11.006

Patel, V.L., Kaufman, D.R. and Arocha, J.F. (2002), "Emerging paradigms of cognition in medical decisionmaking”, Journal of Biomedical Informatics, Vol. 35 No. 1, pp. 52-75. https://doi.org/10.1016/S15320464(02)00009-6

Popovic, V. (2004), "Expertise development in product design e strategic and domain-specific knowledge connections", Design Studies, Vol. 25 No. 5, pp. 527-545. https://doi.org/10.1016/j.destud.2004.05.006

Rowe, R.M. and McKenna, F.P. (2001), "Skilled anticipation in real-world tasks: measurement of attentional demands in the domain of tennis", Journal of Experimental Psychology: Applied, Vol. 7 No. 1, pp. 60-67. https://doi.org/10.1037/1076-898X.7.1.60

Seitamaa-Hakkarainen, P. and Hakkarainen, K. (2001), “Composition and Construction in Experts' and Novices' Weaving Design”, Design Studies, Vol. 22 No. 1, pp. 44-66. https://doi.org/10.1016/S0142-694X(99)00038-1

Simon, H.A. (1973), "The structure of ill structured problems", Artificial Intelligence, Vol. 4 No. 3-4, pp. 181201. https://doi.org/10.1016/0004-3702(73)90011-8

Smyth, M.M. and Pendelton, L.R. (1994), "Memory for movement in professional ballet dancers", International Journal of Sport Psychology, Vol. 25 No. 3, pp. 282-294.

Sörensen, C.A., Jagtap, S. and Warell, A. (2016), "Material selection in industrial design education-a literature review", International Conference on Engineering and Product Design Education, Denmark.

Strauss, A.L. (1987), Qualitative analysis for social scientists, Cambridge University Press. https://doi.org/10.1017/CBO9780511557842

Tovey, M. (1997), "Styling and design: intuition and analysis in industrial design”, Design Studies, Vol. 18 No. 1 , pp. 5-31. https://doi.org/10.1016/S0142-694X(96)00006-3

Tovey, M., Porter, S. and Newman, R. (2003), "Sketching, concept development and automotive design", Design Studies, Vol. 24 No. 2, pp. 135-153. https://doi.org/10.1016/S0142-694X(02)00035-2

Warell, A. (2001), Design Syntactics: A functional approach to visual product form Theory, Models, and Methods, $\mathrm{PhD}$ thesis, Chalmers University of Technology.

Dr. Santosh Jagtap

Blekinge Institute of Technology, Product Development Research Lab

Blekinge Institute of Technology, 37179 Karlskrona, Sweden

Email: santosh.jagtap@bth.se 